\title{
How Formulating Implementation Plans and Remembering Past Actions Facilitate the Enactment of Effortful Decisions
}

\author{
UTPAL M. DHOLAKIA ${ }^{1 *}$, RICHARD P. BAGOZZI ${ }^{2}$ and MAHESH GOPINATH ${ }^{3}$ \\ ${ }^{1}$ Jesse H. Jones Graduate School of Management, Rice University, Houston, \\ Texas, USA \\ ${ }^{2}$ Stephen M. Ross School of Business, University of Michigan, Ann Arbor, Michigan, \\ USA \\ ${ }^{3}$ College of Business \& Public Administration, Old Dominion University, Norfolk, \\ Virginia, USA
}

\begin{abstract}
Building on prior research studying effortful decision making and enactment processes (Bagozzi, Dholakia, \& Basuroy, 2003; BDB), we identify and provide an in-depth understanding of two specific self-regulatory strategies: (1) formulating an implementation plan, and (2) remembering past actions, that decision makers can use in facilitating enactment of effortful decisions. The results of three experiments, in which the decision maker's goal and self-regulatory strategy were manipulated, showed that for goals that decision makers chose volitionally, the motivational effects of both these strategies lay in increasing levels of proximal implementation-related variables (implementation intentions, plan completeness, plan enactment, and goal realization) significantly. In contrast, for goals that were assigned to participants, these strategies' motivational effects additionally extended to significantly increasing distal goal-related variables (goal desire, goal intentions, perceived self-efficacy, and implementation desires). The theoretical implications of our findings are discussed, and future research opportunities are explored. Copyright (C) 2007 John Wiley \& Sons, Ltd.
\end{abstract}

KEY WORDS effortful decision making; implementation plans and intentions; goal striving; motivation and decision making; planning

\section{INTRODUCTION}

Many decisions are effortful to enact. For example, each New Year's Eve, approximately one hundred million Americans choose one or more resolutions to achieve during the upcoming year, such as starting an exercise regimen (37\% of respondents), eating healthier food (13\%), and reducing consumption of tobacco, alcohol, caffeine, or other stimulants (7\%; Miller \& Marlatt, 1998). Interestingly, even though two-thirds (67\%) of the

\footnotetext{
* Correspondence to: Utpal M. Dholakia, Rice University, Jesse H. Jones Graduate School of Management, 6100 Main Street, Houston, TX 77005-1892, USA. E-mail: dholakia@ rice.edu
} 
respondents in Miller and Marlatt's (1998) study made three or more such resolutions, only 25\% reported attaining even one of their resolutions successfully afterward.

As this example illustrates, perhaps the most significant aspect of a decision's value lies in its successful enactment after it has been made. The issue of enactment is particularly crucial for those decisions that involve effort to enact, for one reason or another. Take the resolution of losing weight which many people make each New Year's Eve. Although relatively straightforward to decide, enacting it successfully may involve any number of challenges that the decision maker must overcome. In other cases, enactment may be imposed upon individuals on account of their job responsibilities, social obligations, environmental contingencies, and so forth (Erez, Gopher, \& Arzi, 1990; Latham \& Saari, 1979). Here, even though the initial decision is not made volitionally by the individual, she/he must still enact it by selecting and then carrying out appropriate actions.

By and large, decision researchers have focused on studying issues of choice (e.g., which and how many New Year's resolutions to choose), whereas action psychologists have concerned themselves primarily with enactment issues (e.g., how to pursue and achieve the chosen New Year's resolutions; Bagozzi, Dholakia, \& Basuroy, 2003; Deci \& Ryan, 2000; Hoffman \& Yates, 2005). Our perspective in this research is that this decision making-action psychology divide between choice and decision enactment is artificial and non-productive; rather, we suggest that decision making researchers should concern themselves with decision enactment issues (see also Hoffman \& Yates, 2005).

Perugini and Conner (2000) proposed a general theory of decision making for reflective decisions (Betsch, Haberstroh, Glöckner, Haar, \& Fiedler, 2001), distinguishing between goal desires, goal intentions, behavioral desires, and behavioral intentions, among other variables traditionally found in attitude theory. Building on their theory, recent behavioral decision making research has described the process by which effortful decisions are made and enacted (Bagozzi et al., 2003, BDB henceforth; Dholakia \& Bagozzi, 2002). Drawing upon such theoretical frameworks as image theory (Beach, 1990), the model of action phases (Gollwitzer, 1996), and differentiation and consolidation theory (Svenson, 1997), as well as Perugini and Conner's (2000) research, BDB's model elaborated on the distinction between goals, that is, the outcomes or end-points the decision maker would ultimately like to reach, and plans, the particular means through which the end-point(s) would be attained (Bagozzi \& Dholakia, 1999). It is worth noting that such a distinction is consistent with the view of image theory research which distinguishes between the trajectory image (the decision maker's goal agenda) and the strategic image (plans that are relevant to attainment of goals in the trajectory image; Beach \& Mitchell, 1998).

Corresponding to goals and plans, BDB described two components of an effortful decision: the goal intention, which refers to the decision maker's self-commitment to achieve a particular goal, and the implementation intention, which involves his or her self-commitment to implementing whatever actions are necessary for goal attainment. BDB's model can be characterized as a motivational decision making model, explicitly considering desires which precede the intentions: goal desire in the case of goal intentions, and implementation desire in the case of implementation intentions ${ }^{1}$. In their empirical study, BDB found that the decision maker's desires for the goal and the means mediated the effects of other antecedent variables on to the respective intentions constructs.

In spite of these contributions, two issues with BDB's study must be pointed out. First, because their study was a survey employing a structural equation modeling methodology, BDB were not able to examine how (i.e., through what cognitive and/or motivational processes), formulating an implementation plan ${ }^{2}$ explicitly, facilitates the enactment of effortful decisions. In fact, they acknowledged that 'experiments would be needed to address these issues' (p. 293). BDB also did not study the role of alternative self-regulatory strategies, such as remembering past actions to attain a similar goal that decision makers could use effectively instead.

\footnotetext{
${ }^{1}$ Note that 'implementation desire' in the BDB model is conceptually similar to the 'behavioral desire' construct proposed by Perugini and Conner (2000).

${ }^{2}$ By 'implementation plan' we mean a plan specifying when, where, how, and how long the actions necessary for enacting the decision will be carried out by the decision maker. In cognitive terms, it may be viewed as a set of prospective cognitions to enact a goal-directed behavior given that a future contingency occurs, such as: 'I will perform action $\mathrm{X}$ at time $\mathrm{Y}$ or when situation $\mathrm{Z}$ arises ...'.
} 
The other issue is that BDB studied effortful decision making regarding one particular type of goals, namely goals that the decision maker has chosen volitionally, of his or her own accord. Examples of 'volitionally chosen' goals are selecting a university to attend, donating blood, getting flu shots, achieving a desired body weight, etc. that a decision maker chooses oneself. However, another distinct type of effortful decision making that BDB did not study concerns goals that are assigned to the individual by an external agent who may have some authority over him or her (Latham \& Saari, 1979; Locke, Alavi, \& Wagner, 1997). Examples of assigned goals include a particular project given to a manager by his boss, an assignment given to a student by her teacher to complete over the weekend, etc. In such cases, the specific actions must still be chosen and enacted by the individual, and they involve foresight and effort ${ }^{3}$ (Locke \& Latham, 2002).

On the one hand, motivational research suggests that the origin and bases of motivation for assigned goals are largely external (Carver \& Scheier, 1998; Deci \& Ryan, 2000; Lepper \& Gilovich, 1981) in contrast to volitionally chosen goals that are usually self-motivated. On the other hand, research on goal commitment has shown that holding goal difficulty constant, performance does not differ significantly for decision makers pursuing these two types of goals (Latham \& Saari, 1979; Locke et al., 1997). So, although it is possible there could be significant differences in how these self-regulatory strategies facilitate decision enactment for assigned when compared to volitionally chosen goals, this issue needs to be investigated in-depth.

We addressed these two issues in the present research. In particular, we studied the effects of two self-regulatory strategies: (1) formulating an implementation plan, and (2) remembering past actions that decision makers can use to facilitate enactment of their effortful decisions. We used BDB's (2003) conceptual model, and drew upon other research that has examined implementation plans (Brandstätter, Lengfelder, \& Gollwitzer, 2001; Dholakia \& Bagozzi, 2003; Gollwitzer, 1999), and past behavior (Albarracín \& Wyer, 2000; Betsch, Haberstroh, Molter, \& Glöckner, 2004; Ouellette \& Wood, 1998) as theoretical starting points. We then studied which motivational variables in the BDB model are influenced by these strategies for volitionally chosen and assigned goals of individuals. We employed an experimental methodology to do so, and report the results of three experiments, the first two using longitudinal designs.

Building on existing research regarding the motivating effects of implementation plans (Armitage, 2004; Gollwitzer, 1999; Sheeran \& Orbell, 2000), we found remembering past actions for attaining a similar goal to be motivating for the decision maker. This provides a second distinct strategy for facilitating enactment of effortful decisions. Furthermore, we also found different effects of implementation plans and remembering past actions on the enactment process for volitionally chosen when compared to assigned goals.

Our findings contribute to the behavioral decision making literature by providing an in-depth understanding of two self-regulatory strategies through which effortful decision enactment may be facilitated by decision makers. More broadly, we seek to broaden the focus of decision making researchers by explicitly studying decision enactment within a theoretical framework that also includes choice. Our results also contribute to the social psychology literature on goal-directed behavior (Brandstätter et al., 2001; Gollwitzer, 1999), by studying the effects of remembering past actions, which prior research has not considered. Finally, they extend current knowledge regarding the functioning and effects of implementation plans by showing that plans raise levels of distal goal-related variables such as goal desire and goal intentions, when goals are assigned to decision makers by others.

\section{THEORETICAL OVERVIEW AND RESEARCH HYPOTHESES}

\section{A summary of the BDB model}

A useful starting point for our discussion is the BDB (2003) model of effortful decision making and enactment. Figure 1 graphically depicts our adaptation of this model, showing the variables that we study in

\footnotetext{
${ }^{3}$ Note that the same goal could be volitionally chosen or assigned in different cases. For example, a decision maker may decide to lose weight by oneself (volitionally chosen goal), or may be advised by a doctor to do so (assigned goal).
} 


\section{Goal-related variables;}

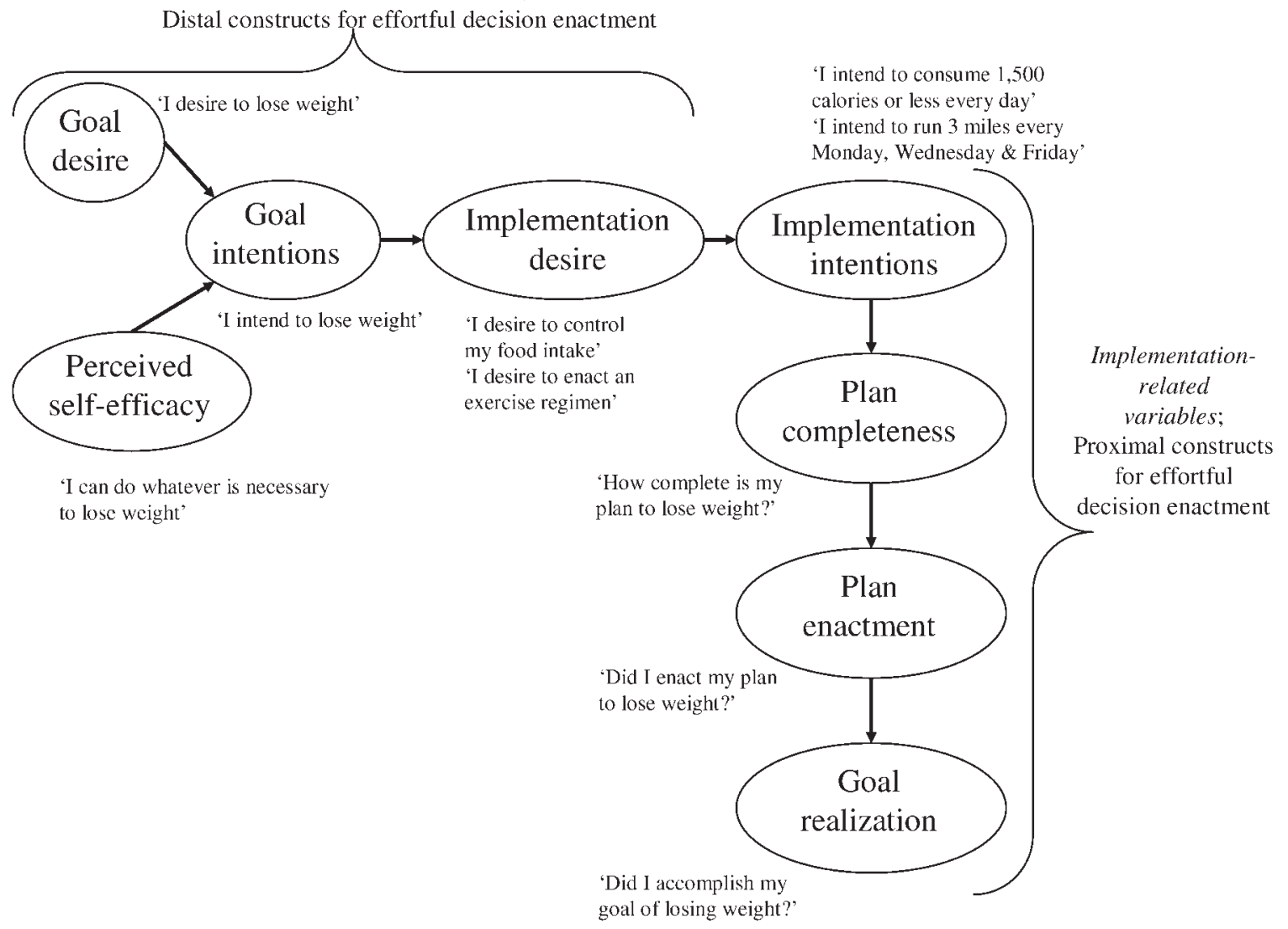

Figure 1. The process of making and enacting effortful decisions

the current research. We included these variables because of their motivational significance to the decision enactment process. The example of a weight loss decision is used in the figure to illustrate the process.

\section{Goal-related (distal) processes of effortful decision enactment}

According to BDB (2003; see also Bagozzi \& Dholakia, 1999; Dholakia \& Bagozzi, 2002), the process of effortful decision making is hierarchical. Individuals first select and adopt a goal they would like to achieve by evaluating the desirability and feasibility of goal alternatives available to them. Depending on task characteristics such as number of options to be considered, personal importance of outcome(s), etc., the decision maker may use either analytical strategies or simple heuristics or both, in choosing the goal, for example, to lose weight (Beach, 1990; Svenson, 1997; see Yates, 1990, for a review).

Choosing to lose weight implies that the decision maker experiences a 'goal desire,' characterized by a certain motivational intensity to attain the goal of losing weight. This motivation is expressed through cognitive and/or conative acts of persistence in the face of difficulties, temptations, and competing goals. Naturally, when the goal is assigned instead of being selected volitionally, the individual will likely not go through an initial goal selection process, but may still feel a goal desire if attainment is viewed as an obligation of group membership, an expression of group identity, or a means to other intrinsically-valued ends such as praise from one's superior, increased prestige within one's social circle, etc. (Heckhausen \& 
Kuhl, 1985). Goal desire leads to 'goal intentions,' which is operationalized in the BDB model by the decision maker's commitment to the chosen goal, and expressed as 'I intend to lose weight.' Note that this construct is congruent to the goal commitment construct in the decision making literature (Locke, Latham, \& Erez, 1988; Sue-Chan \& Ong, 2002).

One construct not considered directly by BDB, but one that we include in the present analysis (Figure 1) due to its motivational importance and agentic functioning ${ }^{4}$, is the decision maker's perceived self-efficacy (Bandura, 1997; Bandura \& Locke, 2003). Perceived self-efficacy is the decision maker's belief in one's own agency, that is, that one has the capacity to do whatever is necessary (e.g., organize, create, and execute actions) to achieve the goal. In the model presented in Figure 1, perceived self-efficacy is an antecedent to goal intentions. This path is based on the large body of research on perceived self-efficacy (Bandura, 1997; DiClemente, Prochaska, \& Gilbertini, 1985; Locke et al., 1988) which has found it to be a determinant of people's engagement and persistence in effortful tasks, and to increase the decision maker's commitment to the goal being pursued (Locke \& Latham, 2002; see Bandura \& Locke, 2003, for a review).

In the BDB model, a construct derived from the Theory of Planned Behavior (Ajzen, 1991), perceived behavioral control (PBC) was included that we omit. We do so because PBC functions at a lower level of abstraction in the decision making hierarchy: it reflects the decision maker's sense of control over performing the chosen actions in the service of decision enactment, and contributes to the selection of actions in pursuing the goal. It is primarily cognitive, rather than motivational, in its functioning (Manstead \& van Eekelen, 1998; Terry \& O’Leary, 1995).

Forming a goal intention leads to a desire to perform whatever actions are necessary to attain the chosen goal. An 'implementation desire' characterizes the decision maker's overall motivation to act in the service of decision enactment. In the case of a weight loss goal, implementation desire may be expressed variously as 'I desire to control my food intake,' 'I desire to enact an exercise regimen,' etc. Since this motivation is an upshot of internalizing the goal decision (regardless of whether the goal is volitionally selected or assigned), it is included as the final goal-related variable in our model in Figure 1. When goals are assigned to the individual, but the means to reach it are not explicitly given, this stage in the process provides the first opportunity for the person to make decisions by oneself, that is, regarding how the assigned goal will be pursued and achieved.

We call the four variables - goal desire, goal intentions, perceived self-efficacy, and implementation desire-collectively, 'distal' goal-related variables, to emphasize their early role in goal-directed decision making, their higher level of abstraction, and because they precede the implementation-related processes that the decision maker must go through to complete effortful decision enactment successfully.

\section{Implementation-related (proximal) processes of effortful decision enactment}

The desire for implementing actions leads the decision maker to consider and evaluate specific behaviors that could be performed to accomplish the goal. The decision maker now moves to a lower level of abstraction in the decision making hierarchy from the goal to the action plan (Carver \& Scheier, 1998). As in the case of goal desire, implementation desire leads to 'implementation intentions,' which is marked by a self-commitment toward doing the actions necessary for goal realization. In the case of the weight loss goal, implementation intentions could be expressed as 'I intend to consume 1,500 calories or less every day,' 'I intend to run 3 miles every Monday, Wednesday, and Friday,' etc.

The final two variables in BDB's conceptual model (and in our adaptation, see Figure 1) are 'plan enactment' and 'goal realization.' Plan enactment represents the degree to which the decision maker

\footnotetext{
${ }^{4}$ The term 'agentic' is used as referring to active attempts by the decision maker to manipulate the environment to enact his or her chosen goal (Crockett, 2002, for a detailed discussion).
} 
successfully implements the action plan, if one was made, when the opportune time arrives ('Did I enact my plan to lose weight?'). Goal realization reflects the final successful (or unsuccessful) attainment of the decision maker's goal ('Did I accomplish my goal of losing weight?'). To conceptually distinguish between plan enactment and goal realization, we note that one's chosen or assigned goals can be realized successfully even when the initially selected (or assigned) plan is not enacted or when there is no plan to begin with. For instance, a decision maker may initially choose a plan involving adherence to an extreme low-calorie diet to lose one's unwanted body weight, but may subsequently realize that a more moderate diet coupled with regular exercise will be more feasible, and enact such behaviors instead. In this case, the original plan is not enacted, yet the decision maker's original goal is realized successfully.

Furthermore, although planning is implicit to three variables shown in Figure 1, for implementation desire, implementation intentions, and plan enactment, it is not required. In particular, because many goals (especially effortful ones), have numerous different routes of implementation, decision makers may oftentimes not formulate a detailed action plan explicitly, relying instead on reacting to opportunities to act as and when they present themselves (Dholakia \& Bagozzi, 2003).

For example, once a decision maker has made a resolution to lose weight, such a goal can be accomplished through various means such as curtailing one's alcohol intake, curbing sugary foods, adopting a low-carb or a low-fat (but not both!) diet, exercising vigorously, taking appetite-suppressing drugs, and so on. In such cases, it may be quite cumbersome (and even detrimental) for many people to formulate a detailed action plan specifying the when, where, how, and how long aspects of every future behavior.

Implementation desire and intentions can both be construed in a non-specific sense, and defined in terms of the motivation and commitment to perform whatever actions are needed to enact the decision of losing weight. Developmental psychologists have referred to the accompanying mental states in such cases as 'planning in action' (Meyer \& Rebok, 1985). However, the actual degree of planning may vary on a continuum for different individuals, with a detailed plan outlining every action on the one end, and a diffuse readiness to act, without any reference to specific actions on the other. To capture this variation in explicit planning among decision makers, we include an additional variable of 'plan completeness' in between implementation intentions and plan enactment in Figure 1, which BDB's model did not have. For the weight loss goal, plan completeness could be expressed as 'How complete is my plan to lose weight?'

We call these four variables - implementation intentions, plan completeness, plan enactment, and goal realization-collectively, 'proximal' implementation-related variables, to emphasize that they are lower in abstraction than the goal-related variables, and are nearer to the decision's actual enactment (see also Carver $\&$ Scheier, 1998). Plan enactment and goal realization map on to the 'performance' construct widely used by decision researchers (Locke et al., 1988).

To summarize, in many real-world settings to which the BDB decision making model applies, instead of being planned in advance, actions may evolve naturally and dynamically, as decision makers come across opportunities to act (Meyer \& Rebok, 1985). We study the benefits of formulating explicit implementation plans beforehand or remembering actions performed in the past under similar circumstances for two types of goals: (1) those that are volitionally chosen by decision makers, and (2) those that are assigned to them by others.

\section{The role of implementation plans in effortful decision making and enactment}

Extant social psychological research has found that forming specific action plans serves several useful purposes (Brandstätter et al., 2001; Gollwitzer, 1999; Sheeran \& Orbell, 2000). First, they mentally link a particular anticipated environmental context to the specific behaviors to be performed, enabling the decision maker to automatically carry out the actions when the environmental context occurs or is encountered (Gollwitzer, 1999). This is the cognitive function of implementation plans. 
Second, they help decision makers to get started on their goals by initiating the required actions at the right time. For example, in a study conducted by Gollwitzer and Brandstätter (1997), some participants were instructed to form a plan by choosing favorable opportunities to express counter-arguments against xenophobic statements, and others were not. When participants were later allowed to counter-argue, those forming a plan were able to seize suitable opportunities for expressing themselves more readily (see also Brandstätter et al., 2001). This and other studies have shown that plans create a perceptual readiness, guiding the person's attention toward available opportunities for acting. This is the volitional or conative function of implementation plans.

Third, forming a plan reduces conflict. By choosing a particular course of action over others, the decision maker increases commitment to this action course, as findings on the endowment effect (Kahneman, Knetsch, $\&$ Thaler, 1991) and the sunk cost effect (Arkes \& Ayton, 1999) have shown. Fourth, detailed plans foster an inflated sense of optimism increasing perceptions of self-efficacy regarding decision enactment (Gollwitzer, 1996). They may do so by providing a plausible scenario of the future, and the specific path leading to it (Beach, 1990). Finally, planning supports the progress of initiated goal pursuits by mobilizing effort in the face of difficulties, and warding off distractions during the process of effortful decision enactment (Brandstätter et al., 2001). These are the motivational functions of implementation plans.

A key implication of these findings is that relative to decision makers not forming an explicit plan, those forming one, should become more committed to the chosen (planned) course of action, and have higher levels of implementation intentions. Not surprisingly, by virtue of having formed a plan, participants should report a higher level of plan completeness relative to those not forming a plan. Planning should also lead to a significantly greater degree of enactment of this chosen plan, when compared to the case when a plan is not available for enactment. Finally, through automating the execution of actions and by facilitating the initiation of goal-directed action at opportune time(s), implementation plans should facilitate realization of the chosen goal to a significantly greater extent (Gollwitzer \& Brandstätter, 1997; Sheeran \& Orbell, 2000).

Armitage (2004) recently showed such effects of implementation plans for assigned effortful goals as well. Upon assigning to participants the goal of eating a low-fat diet for a month, he found that those participants who were further asked to form a detailed implementation plan were able to reduce their fat intake significantly a month later, relative to participants who had not formed such an implementation plan. Similarly, Sheeran and Orbell (2000) showed that an implementation intention intervention increased attendance at an (assigned) cervical cancer screening by more than $30 \%$ when compared to a control group.

Summarizing this discussion, we predict that the effects of forming explicit implementation plans on implementation-related variables in the BDB model will occur for both volitionally chosen and assigned goals. Our hypothesis is:

Hypothesis 1: Participants forming an implementation plan will have higher levels of (a) implementation intentions, (b) plan completeness, (c) plan enactment, and (d) goal realization, relative to those not forming an implementation plan, for both volitionally chosen and assigned goals.

In action theoretic formulations of goal-directed behavior, mindsets play an important role (Brandstätter \& Frank, 2002; Gollwitzer, 1996). Decision makers adopt different mindsets, or cognitive orientations, in the pre-decisional and post-decisional stages, which influence how they process information and how they behave. Prior to goal choice, the decision maker's orientation is directed toward evaluation, by considering the desirability and feasibility of each option, and comparing them to one another. In this 'deliberative mindset,' the decision maker is receptive to new information that will help in goal selection.

In contrast, after the goal is chosen, the decision maker gives attention to execution issues, leading to an 'implemental mindset.' This mindset is marked by closed-or single-mindedness toward new information, and instead focuses on opportunities to initiate and enact behaviors. The distinction between deliberative and implemental mindsets is helpful in understanding how the goal-related variables in Figure 1 will be affected 
by plan formation. We expect that the type of goal—whether volitionally chosen or assigned-will be crucial in determining these effects.

Consider volitionally chosen goals first. The decision maker has already chosen the goal, and has passed through the deliberative mindset. In action psychology terms, the decision maker has 'crossed the Rubicon ${ }^{5}$, (Gollwitzer, 1996) and is in an implemental mindset (Gollwitzer, Heckhausen, \& Katajczak, 1990). Forming an implementation plan is therefore expected to impact only implementation-related variables for such decisions, but should have no effect on the four goal-related variables. This prediction is in line with recent research on the interplay between goal and implementation intentions that found implementation intentions to influence goal realization only when the relevant goal was activated and the person had strong goal intentions (Sheeran, Webb, \& Gollwitzer, 2005).

On the other hand, the locus of motivation is external when decision makers are assigned a goal (Erez et al., 1990; Lepper \& Gilovich, 1981). This is likely to result in lower initial levels of goal desire, goal intentions, perceived self-efficacy, and implementation desires for assigned goals. Additionally, decision makers with assigned goals are less, if at all, likely to have gone through the deliberative mindset themselves (since the goals are, in a sense, conferred upon them by others). Their personal desires and intentions regarding the goal are likely to be less crystallized. Consequently, formulating a specific implementation plan should significantly benefit the goal-related variables through the processes discussed before. So:

Hypothesis 2: Participants forming an implementation plan will have higher levels of (a) goal desire, (b) goal intentions, (c) perceived self-efficacy, and (d) implementation desires, relative to participants not forming an implementation plan, for goals that are assigned to them. There should be no significant differences in the two participant groups in any of these distal measures for volitionally chosen goals.

It is noteworthy that this hypothesis extends current knowledge regarding the functioning and effects of implementation plans, and if supported, makes a concurrent contribution to the action psychology literature as well.

\section{THE ROLE OF REMEMBERING PAST ACTIONS IN EFFORTFUL DECISION MAKING AND ENACTMENT}

Considerable evidence attests to the importance of past actions in effortful decision enactment (Ajzen, 2002; Albarracín \& Wyer, 2000; Ouellette \& Wood, 1998). This research suggests three conceptually distinct ways in which past actions can influence decision enactment (Bagozzi \& Dholakia, 2005). One perspective is that past actions should be employed as proxies or content-free statistical controls, substituting for consistency-producing variables that are omitted from the model (Ajzen, 2002). A second view is past actions should be treated as predictors of future actions, so that including them in the model attenuates the predictive power of other antecedents to behavior, while they themselves become its significant predictors (Triandis, 1980). Both perspectives are commonly used when describing habitual actions ${ }^{6}$ (see Ouellette \& Wood, 1998, for a review) or routines (Betsch et al., 2004), or more generally studying what decision theorists refer to as 'reflexive decisions' (Betsch et al., 2001). However, these perspectives say little or nothing about the motivational processes through which past actions influence future action enactment, and have been seldom employed in the study of effortfully enacted decisions.

\footnotetext{
${ }^{5}$ Drawing on its historical significance, this phrase is used metaphorically to connote a milestone that separates two significantly different units. In the present case, choice of the goal separates the preceding deliberative mindset from the subsequent implemental mindset. ${ }^{6}$ By habitual actions, we mean learned sequences of actions that have become more or less automated as a result of being performed frequently (Verplanken, Aarts, \& van Knippenberg, 1997).
} 
A third perspective, and one that we employ herein, is that past actions can influence goaldirected behavior through motivational processes. This view is more relevant for infrequently and irregularly enacted decisions, or in decision theory terms, 'reflective' decisions (Betsch et al., 2001). In particular, consider goals such as losing (or gaining) several pounds of body weight, studying continuously for a long stretch of time, forming a romantic relationship, etc. In all these cases, since the goal is chosen and enacted by most people on a relatively infrequent basis, the role played by remembrance of past actions is likely to be different from that for habitual routines (Betsch et al., 2004). We propose explicitly that the recollection of actions performed successfully in the past in the service of a similar goal should have a significant motivational impact on goal and implementation-related variables, facilitating decision enactment.

Remembering previously employed actions renders specific behavioral responses more accessible, along with cues that were encountered in the environment that led to these actions. Research on habits has shown that such a strategy links the prospective environmental context to specific actions that must be performed in the future (Wood, Quinn, \& Kashy, 2002). For example, remembering that one was successfully able to study for an extended time period in the library one afternoon should lead a student to consider visiting the library when faced with a similar goal in the future. Furthermore, by steering the decision maker toward a successfully employed course of action, they should foster the narrowed and execution-oriented mental focus that is characteristic of an implemental mindset (Wood, Tam, \& Guerrero Witt, 2005). Remembering the library study event should reduce the student's likelihood of choosing the park or a neighborhood coffee shop for a future study event, for example.

When there is a time gap between decision making and enactment, the recall of past actions is also likely to facilitate prospective remembering (i.e., memory for future actions; Kvavilashvili \& Ellis, 1996). Past action remembrance is also likely to yield some of the same volitional benefits that a plan does, such as an illusory optimism, warding off distractions, etc., during action execution (Bagozzi \& Dholakia, 2005).

Consequently, based on these prior studies, we expect that the remembrance of past actions should impact the implementation-related variables in much the same way that an implementation plan does. We expect these effects to occur for both volitionally chosen and assigned goals, conditional on the individual having pursued a similar goal successfully in the past. Our hypothesis is:

Hypothesis 3: Participants remembering past actions will have higher levels of (a) implementation intentions, (b) plan completeness, (c) plan enactment, and (d) goal realization, relative to participants not remembering past actions, for volitionally chosen and assigned goals.

Furthermore, we expect the effects of remembering past actions on goal-related variables to depend on the type of goal being pursued. For volitionally chosen goals, the motivational impact of remembering past actions should be less because of the high intrinsic motivation already present when making such decisions. As in the case of implementation plans, remembering past actions should not affect the levels of goal desire, goal intentions, perceived self-efficacy and implementation desire significantly (Sheeran et al., 2005).

In contrast, for assigned goals, the lower level of motivation should be augmented significantly by remembering past actions, not only raising the decision maker's desire and commitment to the assigned goal, but also perceptions of self-efficacy, and desire to enact the behaviors. Research on self-efficacy, which has shown that the remembrance of past performance augments the individual's self-efficacy beliefs regarding enacting similar behaviors in the future (Bandura, 1997) supports this prediction. Such a prediction is also consistent with Ouellette and Wood's (1998) suggestion that making one's past behavior accessible can inform the decision maker's motivation to realize a goal positively through self-perception and the cognitive consistency process. So, we hypothesize that: 
Hypothesis 4: Participants remembering past actions will have higher levels of (a) goal desire, (b) goal intentions, (c) perceived self-efficacy, and (d) implementation desires, relative to participants not remembering past actions, for assigned goals. There should be no differences in the two participant groups in any of these measures for volitionally chosen goals.

The results of three experiments conducted to test these hypotheses are now described.

\section{EXPERIMENT 1: THE ROLE OF IMPLEMENTATION PLANS AND REMEMBERING PAST ACTIONS FOR VOLITIONALLY CHOSEN AND ASSIGNED GOALS}

In this first experiment, we tested all four research hypotheses using a modified version of the methodology used by BDB (2003). Participants completed the study in two waves. In the first wave, they either described a personally important goal that they had chosen recently themselves, or were assigned a goal. Respondents then formed an implementation plan, remembered past actions or did neither (control group), and finally completed a set of measures eliciting the goal-related variables, implementation intentions and plan completeness. Approximately 2 weeks later, in the second wave, they completed measures of plan enactment and goal realization via email.

\section{Method}

\section{Participants and design}

Two hundred eighty-one undergraduate students participated in the experiment in exchange for course credit. There are two manipulated factors in the experiment: (1) Goal type: volitionally chosen or assigned, and (2) Self-regulatory strategy: forming a plan, remembering past actions, or control group. Participants were randomly assigned to one of the six cells.

\section{Manipulation of goal type}

All participants were first instructed: 'Individuals often make decisions regarding important personal goals. These decisions may pertain to asking someone out on a date, losing weight, quitting or reducing smoking, getting good grades on an exam, buying products or services, donating blood, etc.'

Those in the 'volitionally chosen goal' condition were then told: 'In the following pages, we would like to know in great detail about a recent such decision made by you, pertaining to an important personal goal that you now have and that you have also had in the past. Please select one important personal goal that you chose recently which you intend to accomplish in the next 2 weeks (Important: Please exclude goals related to habits such as buying gas or groceries, attending class, etc.).'

Participants in the 'assigned goal' condition were instead instructed: 'An important goal for most college students is to study regularly. In the following pages, we would like you to form a goal of studying for 2 hours continuously this weekend. The goal we want you to form is as follows: Please take a minute and form a goal to study continuously for two hours at any time that is convenient to you this weekend (Friday-Sunday).' Note that the pre-tests with another student sample from the same population had shown that the goal of continuous study was viewed as effortful, and was infrequently pursued by this student group, that is, fewer than two times a month on average, during the academic year.

\section{Manipulation of self-regulatory strategy}

Participants in the 'forming a plan' condition then formed a detailed action plan to achieve their goal. Separate questions regarding what actions they would take, when, where, how, and how long, to achieve their goal were asked to help participants form their plan. Respondents in the 'remembering past actions' condition 
Table 1. Details of measures, Experiment 1

Study measures

First wave measures

Goal desire

$\bigcirc$ My desire to reach the goal that I have chosen (study continuously for 2 hours this weekend) can best be described as: (7-point scale)

Goal intentions

The strength of my actual intention to pursue the goal I described above (study for 2 hours continuously

this weekend) can best be described as: (6-point scale)

Perceived self-efficacy

$\bigcirc$ I feel confident that I can achieve my chosen goal in the next 2 weeks (study for 2 hours continuously this weekend): (5-point scale)

Implementation desire

$\bigcirc$ My desire to perform the actions necessary to achieve my goal during the next 2 weeks (study for 2 hours continuously this weekend) can best be expressed as: (7-point scale)

Implementation intentions

The strength of my actual intention to perform the actions needed to achieve my personal goal in the next

2 weeks (study for 2 hours continuously this weekend) can best be described as: (6-point scale)

Second wave measures

Plan completeness

I have a plan of action to carry out my decision in the next 2 weeks: (7-point scale)

$\bigcirc$ The plan I have made to carry out my decision can be considered to be complete: (5-point scale)

Plan enactment

I was able to do things exactly as I had planned to achieve my goal: (7-point scales for all items)

I achieved my goal exactly WHEN I had planned

I achieved my goal exactly WHERE I had planned

$\bigcirc$ I achieved my goal exactly HOW I had planned

I achieved my goal in exactly AS LONG AS I had planned

Goal realization

I was successful in acting on my decision described above during the last 2 weeks (studying for 2 hours continuously last weekend): (7-point scale)

were instead instructed to remember the last time they had performed the actions to successfully accomplish a similar goal. They were asked open-ended questions regarding what specific actions they had taken the last time, as well as when, where, how, and how long they performed actions to reach their goal the last time. All three groups then completed the study measures (Table 1).

\section{Second-wave method}

Two weeks later, participants were sent a short customized follow-up survey by email. After briefly describing their goal (to remind them), we asked questions regarding whether they had realized their goal and whether they had enacted their plan (Table 1). To minimize demand effects (i.e., participants feeling obligated to respond that they had achieved the goal), we used the procedure used by Gollwitzer and Brandstätter (1997). Specifically, we made no mention of participants' names or other identifying personal information in our correspondence, and also emphasized that there were no right or wrong responses to the questions. Of the 284 first-wave participants, 219 (or 77\%) responded to this second-wave survey ${ }^{7}$.

\footnotetext{
${ }^{7}$ We compared the non-respondents to the second-wave respondents along all the first wave measures: goal desires, perceived self-efficacy, goal intentions, implementation desire, and implementation intentions. One-way ANOVAs revealed no significant differences for any of the measures.
} 


\section{Measures}

Except for self-efficacy, our measures were the same as those of BDB (2003). These measures have high reliabilities and have been shown to achieve convergent and discriminant validity by BDB. The study measures are provided in Table 1.

\section{Results}

Preliminary analyses

Past experience with the goal. To ensure equivalence in respondents' past experience levels across experimental conditions, we only included data of respondents who had attained a similar goal (as the one that they chose volitionally or was assigned to them) at least once in the past 3 months. Data of three respondents who were pursuing their goal for the very first time were discarded, leaving a usable sample size of 281. We also measured the number of times in the past year each respondent had tried to attain the goal. Our results do not vary whether or not we include this variable as a covariate in our tests of hypotheses reported below.

Measure reliability. The bivariate correlation for the two plan completeness items collected in the first wave was 0.76, and the Cronbach $\alpha$ for the five plan enactment measures in the second wave was 0.91. Since this indicated adequate reliability, these measures were averaged respectively, to obtain single dependent measures of plan completeness and plan enactment. All other constructs had single measures (Table 1).

\section{Tests of hypotheses}

To test the research hypotheses, multivariate analyses of variance (MANOVAs) were conducted in each case, for the respective group of dependent variables (goal-related and implementation-related), and were followed up with 2 goal type $\times 3$ self-regulatory strategy ANOVAs for each dependent variable. The results are provided are in Table 2 .

Table 2. Mean levels of dependent measures by goal type and self-regulatory strategy type, Experiment 1

\begin{tabular}{|c|c|c|c|c|c|c|}
\hline \multirow[b]{2}{*}{ Dependent measures } & \multicolumn{3}{|c|}{ Volitionally chosen goal } & \multicolumn{3}{|c|}{ Assigned goal } \\
\hline & $\begin{array}{l}\text { Control group } \\
\quad(N=53)\end{array}$ & $\begin{array}{l}\text { Past actions } \\
\text { group }(N=57)\end{array}$ & $\begin{array}{c}\text { Imp. plan } \\
\text { group }(N=53)\end{array}$ & $\begin{array}{l}\text { Control group } \\
\quad(N=44)\end{array}$ & $\begin{array}{l}\text { Past actions } \\
\text { group }(N=36)\end{array}$ & $\begin{array}{l}\text { Imp. plan group } \\
\qquad(N=38)\end{array}$ \\
\hline Goal desire & 5.83 & 5.80 & 5.98 & 3.66 & $4.28^{*, \mathrm{a}}$ & $4.89^{* * *, \mathrm{~b}}$ \\
\hline Goal intentions & 3.98 & 3.79 & 4.12 & 3.75 & $4.47^{* *, \mathrm{a}}$ & $4.68^{* * *, \mathrm{~b}}$ \\
\hline Perceived self-efficacy & 4.92 & 4.80 & 5.10 & 3.80 & 3.97 & 4.16 \\
\hline Implementation desires & 4.96 & 5.27 & 5.39 & 4.00 & $4.75^{* *, \mathrm{a}}$ & $5.26^{* * *, \mathrm{~b}}$ \\
\hline $\begin{array}{l}\text { Implementation } \\
\text { intentions }\end{array}$ & 4.42 & $4.87^{* *, \mathrm{a}}$ & $4.98^{* * *, \mathrm{~b}}$ & 3.98 & 4.31 & $4.84^{* * *, \mathrm{~b}}$ \\
\hline Plan completeness & 4.01 & $4.54^{* *, \mathrm{a}}$ & $4.95^{* * *, \mathrm{~b}}$ & 3.72 & $4.33^{* *, \mathrm{a}}$ & $4.92^{* * *, \mathrm{~b}}$ \\
\hline Plan enactment & 3.72 & 4.02 & 4.08 & 3.64 & $4.42^{* *, a}$ & $4.64^{* * *, \mathrm{~b}}$ \\
\hline Goal realization & 3.82 & $4.54^{* *, \mathrm{a}}$ & $4.71^{* *, \mathrm{~b}}$ & 3.80 & $5.00^{* * *, a}$ & $5.14^{* * *, \mathrm{~b}}$ \\
\hline
\end{tabular}


H1: Effects of forming implementation plan on implementation-related variables. Recall that $\mathrm{H} 1$ proposed that forming an implementation plan would raise the level of the four implementation-related variables significantly for both goals. For volitionally chosen goals, to test H1 for implementation intentions, a MANOVA for the four variables yielded a significant main effect $(\mathrm{F}(4,71)=5.91, p<0.001)$, supporting $\mathrm{H} 1$. Follow-up ANOVAs showed that levels of three of the four implementation-related variables were higher for those forming a plan when compared to the control group: implementation intentions $\left(M_{\text {plan }}=4.98\right.$ vs. $\left.M_{\text {control }}=4.42, p<0.001\right)$, plan completeness $\left(M_{\text {plan }}=4.95\right.$ vs. $\left.M_{\text {control }}=4.01, p<0.001\right)$, and goal realization $\left(M_{\text {plan }}=4.71\right.$ vs. $\left.M_{\text {control }}=3.82, p<0.05\right)$. However, the levels were not different for plan enactment $\left(M_{\text {plan }}=4.08\right.$ vs. $M_{\text {control }}=3.72$, n.s. $)$. Overall, these results largely support $\mathrm{H} 1$ for volitionally chosen goals.

For assigned goals, the results were stronger. Results of a MANOVA revealed a significant main effect (F $(4,73)=5.42, p<0.001)$. ANOVAs for all four implementation variables revealed that those forming an implementation plan reported significantly higher levels for each individual variable when compared to the control group: implementation intentions $\left(M_{\text {plan }}=4.84\right.$ vs. $\left.M_{\text {control }}=3.98, p<0.001\right)$, plan completeness $\left(M_{\text {plan }}=4.92\right.$ vs. $\left.M_{\text {control }}=3.72, p<0.001\right)$, plan enactment $\left(M_{\text {plan }}=4.64\right.$ vs. $\left.M_{\text {control }}=3.64, p<0.001\right)$, and goal realization $\left(M_{\text {plan }}=5.14\right.$ vs. $\left.M_{\text {control }}=3.80, p<0.001\right)$. These results strongly support $\mathrm{H} 1$ for assigned goals.

H2: Effects of forming implementation plan on goal-related variables. Recall our hypothesis was that we would find significant differences between those forming a plan and the control group for assigned goals, but not for volitionally chosen goals. Consider the results for assigned goals first in Table 2. Results of a MANOVA revealed a significant main effect $(\mathrm{F}(4,77)=4.92, p<0.001)$. In three of the four cases, goal desire $\left(M_{\text {plan }}=4.89\right.$ vs. $\left.M_{\text {control }}=3.66, p<0.001\right)$, goal intentions $\left(M_{\text {plan }}=4.68\right.$ vs. $M_{\text {control }}=3.75$, $p<0.01)$, and implementation desires $\left(M_{\text {plan }}=5.26\right.$ vs. $\left.M_{\text {control }}=4.00, p<0.001\right), \mathrm{H} 2$ is supported since the differences are statistically significant. However, the difference for perceived self-efficacy $\left(M_{\text {plan }}=4.16\right.$ vs. $M_{\text {control }}=3.80$ ) was not significant.

For volitionally chosen goals, a MANOVA revealed no effect of the goal-related variables (F (4, $100)=0.44$, n.s.). Individual ANOVAs confirmed that there are no significant differences in levels of any of the four goal-related variables between those forming an implementation plan and those not forming one, providing support to $\mathrm{H} 2$.

H3: Effects of remembering past actions on implementation-related variables. Our hypothesis was that remembering past actions would raise the level of all four variables significantly for both goals relative to the respective control groups. MANOVAs for both goals again supported this hypothesis, revealing significant effects. More specifically, in the case of volitionally selected goals, H3 is supported for three (except plan enactment) of the four variables. Likewise, for assigned goals, it is supported for three (except for implementation intentions) of the variables (see Table 2 for details).

H4: Effects of remembering past actions on goal-related variables. Like $\mathrm{H} 2$, we expected a significant impact of remembering past actions for assigned goals but not for volitionally selected goals. Considering assigned goals first, a MANOVA revealed a significant main effect $(\mathrm{F}(4,75)=2.39, p=0.05)$, and the individual ANOVA results for goal desire $\left(M_{\text {pastaction }}=4.28\right.$ vs. $\left.M_{\text {control }}=3.66, p<0.05\right)$, goal intentions $\left(M_{\text {pastaction }}=4.47\right.$ vs. $\left.M_{\text {control }}=3.75, p<0.01\right)$, and implementation desires $\quad\left(M_{\text {pastaction }}=4.75\right.$ vs. $M_{\text {control }}=4.00, p<0.05$ ), all supported H4. The difference is in the expected direction but not statistically significant for perceived self-efficacy. For volitionally selected goals, none of the four variables were significantly different whether past actions were remembered or not, providing support to $\mathrm{H} 4$. 
Mediation analysis. To determine whether the effect of remembering past actions on goal realization occurred independently or was mediated by implementation intentions ${ }^{8}$, we conducted mediation analyses using the procedure suggested by Baron and Kenny (1986). Tests of H3 had already shown significant effects of remembering past actions on (a) implementation intentions, and (b) goal realization, for both goal types. Separate ANOVAs were run for each goal type with two levels of self-regulatory strategy (remembering past actions, control) as the independent factor, goal realization as the dependent variable, and implementation intentions included as a covariate.

For volitionally selected goals, the effects of implementation intentions on goal realization were not significant $(F(1,72)=0.87, p>0.35)$, ruling out mediation, and providing evidence of a solely direct effect of remembering past actions on goal realization. The Sobel test statistic was $1.34(p=0.18)$, confirming this conclusion (Sobel, 1982). For assigned goals, the effects of implementation intentions were significant $(F(1,71)=6.45, p<0.05)$, yet the effects of remembering past actions also remained significant $(F(1,71)=5.43, p<0.05)$ in the ANOVA. The Sobel test statistic in this case was $2.50(p<0.01)$. Taken together, these results indicate that implementation intentions partially mediate the effects of remembering past actions on goal realization for assigned goals.

\section{Discussion}

Overall, the pattern of results in the longitudinal experiment supports the four hypotheses concerning the beneficial roles played by implementation planning and remembering past actions on the motivational variables in the BDB model. However, two potential weaknesses of the study should be pointed out. The first concern is that despite our precautions, the results for plan enactment and goal realization may be susceptible to social desirability effects. In particular, it is possible that participants may have responded in the second wave to remain consistent with their responses to items in the first wave. Such a concern is likely to be accentuated for those who were assigned goals, and is also more pronounced because the dependent variables were collected via self-reports, instead of being observed and recorded by the experimenters.

A second potential concern is that for many participating students, the assigned goal, namely, studying 2 hours continuously on the upcoming weekend, could be self-generated, that is, behavior that they would do anyway. In such cases, decision enactment would be self-motivated instead of being externally imposed on participants. Although the overall pattern of findings did not suggest such a possibility, it would be useful to test our predictions again in a different context where such a potential contamination of assigned goals is not an issue. To address these two concerns, we designed and conducted a second field experiment which is described below.

\section{EXPERIMENT 2: THE ROLE OF IMPLEMENTATION PLANS AND REMEMBERING PAST ACTIONS FOR A NOVEL ASSIGNED GOAL}

In this longitudinal experiment, we assigned the specific goal of visiting a newly created web site to participants during an upcoming 1-week period and completing a questionnaire posted on it. Since respondents had no prior knowledge of this web site, such a goal could not be volitionally chosen by them. We then observed and recorded whether participants actually visited the web site during the specified time-frame, overcoming concerns regarding social desirability effects occurring from self-reported behaviors. Hypotheses 1-4 were re-tested in this study under these different conditions, only for goals assigned to individuals.

${ }^{8}$ We thank a reviewer for suggesting this analysis. 


\section{Method}

A total of 106 undergraduate business students participated in the experiment for a chance to win money. In a class session on judgment and decision making, the study was introduced as an investigation of the 'Overconfidence bias'. Participants were told:

'Many students are prone to a particularly harmful type of problem when making decisions: the Overconfidence Bias. The Overconfidence Bias has been identified as one of the most prevalent and catastrophic problems in decision making, responsible for many negative outcomes including the Pearl Harbor and the Challenger disasters. Experts agree that knowing whether you are susceptible to the Overconfidence Bias is extremely important and will help to make you a better decision maker. Two renowned researchers, Edward Russo and Paul Shoemaker have developed a simple and short survey that takes only a few minutes to measure a person's level of overconfidence. We have designed the following website (which will be online from [date]) that will allow you to find your level of overconfidence by completing the Russo and Shoemaker scale: http://abc.xyz.edu/confidence. In addition, this website will also provide an effective technique to help you to reduce the effects of over-confidence on your decision making, to make better decisions.'

Participants were informed that the web site was still being constructed, and would be available on the stipulated date three days later. Further, due to copyright reasons, they were informed, it would only be available for a limited time period of 1 week thereafter. Participants were instructed to visit the web site during this time, complete the overconfidence scale, and provide their reactions to the researchers. They were also informed that two participants would be randomly chosen to receive $\$ 50$ each from among those who completed the scale.

The main manipulation in this study was of self-regulatory strategy type-forming a plan, remembering past actions, or control group - and was done in the same manner as the first experiment. The measures used were also similar (Table 1). To maintain anonymity, participants were asked to write an identifying word in the questionnaire and then use it again to identify themselves when they visited the web site.

The web site was made available on schedule 3 days later, and remained online for a week thereafter. All participants who visited the web site were recorded by means of their identifying words. This binary variable, whether the participant visited the web site or not, is a key dependent measure in this experiment.

\section{Results}

For ease of exposition, the results for all the dependent measures by group are summarized in Table 3.

\section{Tests of hypotheses}

From Table 3, the pattern of results is similar to that of Experiment 1. Supportive of Hypotheses 1-4, there are significant differences between the planning group and the control group, as well as between the remembering past actions group and the control group for each goal-related measure, and each implementation-related measure. It is noteworthy that here, unlike Experiment 1, we also found a significant increase in perceived self-efficacy for both experimental groups $\left(M_{\text {plan }}=6.14, M_{\text {pastaction }}=6.09\right)$, when compared to the control group $\left(M_{\text {control }}=5.14\right)$.

\section{Decision enactment}

Considering the dependent measure of goal realization, that is, whether participants visited the web site or not during the 1-week time period, results revealed that only $8.3 \%$ of the control group visited the web site. In 
Table 3. Mean levels of dependent measures by group, Experiment 2

\begin{tabular}{|c|c|c|c|c|}
\hline Dependent measures & $\begin{array}{l}\text { Control group } \\
\quad(N=36)\end{array}$ & $\begin{array}{l}\text { Remembering } \\
\text { past actions } \\
\text { group }(N=34)\end{array}$ & $\begin{array}{l}\text { Forming } \\
\text { implement. } \\
\text { plan group } \\
(N=36)\end{array}$ & One-way ANOVA results \\
\hline Goal desire & 3.97 & $5.00^{* * *, a}$ & $4.61^{*, \mathrm{~b}}$ & $\mathrm{~F}(2,106)=4.65, p<0.05, \eta^{2}=0.08$ \\
\hline Goal intentions & 3.75 & $4.41^{*, \mathrm{a}}$ & $4.69^{* * *, \mathrm{~b}}$ & $\mathrm{~F}(2,106)=3.68, p<0.05, \eta^{2}=0.07$ \\
\hline Perceived self-efficacy & 5.14 & $6.09^{* * *, a}$ & $6.14^{* * *, \mathrm{~b}}$ & $\mathrm{~F}(2,106)=7.33, p<0.001, \eta^{2}=0.13$ \\
\hline Implementation desires & 3.92 & $4.76^{* *, \mathrm{a}}$ & $4.75^{* *, \mathrm{~b}}$ & $\mathrm{~F}(2,106)=3.90, p<0.05, \eta^{2}=0.07$ \\
\hline Implementation intentions & 3.83 & $4.53^{*, \mathrm{a}}$ & $4.83^{* * *, \mathrm{~b}}$ & $\mathrm{~F}(2,106)=4.33, p<0.05, \eta^{2}=0.08$ \\
\hline Plan completeness & 3.04 & $4.34^{* * *, a}$ & $5.36^{* * *, \mathrm{~b}}$ & $\mathrm{~F}(2,106)=24.1, p<0.001, \eta^{2}=0.31$ \\
\hline$\%$ Visiting web-site & $8.3 \%$ & $32.4 \% \%^{* * * a}$ & $27.8 \% \%^{* * \mathrm{~b}}$ & $\begin{array}{l}\text { Control vs. Imp Plan: } \chi^{2}(1)=4.60, \\
p<0.05 \\
\text { Control vs. Past Actions: } \chi^{2}(1)=6.31 \text {, } \\
p<0.01\end{array}$ \\
\hline
\end{tabular}

${ }^{*} p<0.05$

${ }^{* *} p<0.01$

${ }^{* * *} p<0.001$.

${ }^{\mathrm{a}}$ Remembering past actions group $>$ control group.

${ }^{\mathrm{b}}$ Forming implementation plan group $>$ control group.

contrast, significantly higher proportions of both self-regulatory strategy groups, $32.4 \%$ of the remembering past actions group $\left(\chi^{2}(1)=6.31, p<0.01\right)$ and $27.8 \%$ of the forming a plan group $\left(\chi^{2}(1)=4.60, p<0.05\right)$, visited the web site?

\section{Discussion}

These results replicate the findings of Experiment 1 for a different assigned goal that could not have been self-generated by participants, and eliminate problems associated with self-reported behavior. They show that either forming an implementation plan, or remembering past actions raises the levels of both distal goal-related variables, and proximal implementation-related variables in the modified BDB model of Figure 1.

Nevertheless, one weakness of this experiment (as well as the first one) must be pointed out. In both these experiments, we tested our hypotheses by comparing levels of the BDB model variables between subjects, and found support for them. To provide stronger support for the hypotheses, especially for $\mathrm{H} 2$ and $\mathrm{H} 4$, it is important to demonstrate within-subject effects. In particular, if our argumentation is valid, we would expect that the levels of goal-related variables, in particular, goal desire, will increase for assigned goals, but will remain unchanged for volitionally selected goals within-subjects ${ }^{10}$. Experiment 3 was conducted to address this issue.

\section{EXPERIMENT 3: THE ROLE OF IMPLEMENTATION PLANS AND REMEMBERING PAST ACTIONS FOR LEVEL OF GOAL DESIRE WITHIN SUBJECTS}

In this experiment, goal desire was measured twice within subjects in the self-regulatory strategy conditions, once prior to the manipulation and then once again, to obtain stronger support for $\mathrm{H} 2$ and $\mathrm{H} 4$. It was measured

\footnotetext{
${ }^{9}$ Mediation analysis using the same procedure as in Experiment One did not find implementation intentions to mediate the effects of remembering past actions on goal realization. Details of this analysis are available from the authors.

${ }^{10}$ We thank a reviewer for suggesting this possibility, and also credit him or her with the idea for Experiment 3.
} 
only once in the control group. As mentioned earlier, we expected there to be a significant increase in goal desire for those respondents who were assigned goals, but not for those who volitionally selected their goal, after both implementation planning and remembering past actions.

\section{Method}

Seventy-eight undergraduate business students participated in the experiment in exchange for course credit. Respondents completed the questionnaire regarding two goals, one that they selected volitionally and the other which was assigned to them. The instructions in each case were identical to those used in Experiment 1. The order in which participants responded to the two goals was counterbalanced between subjects, and since there were no order effects, this variable is not considered further.

Participants were assigned to one of three self-regulatory conditions: forming a plan, remembering past actions, or control group. In the first two cases, participants were given preliminary instructions regarding the goal type (same as in Experiment 1), and their goal desire was measured the first time (see Table 1 for the measure). Participants then completed the self-regulatory task, that is, they either formed a plan or remembered past action, after which the respondent's goal desire was measured again. In the control condition, goal desire was measured only once, following the preliminary instructions.

Our analysis involved two comparisons within each goal type: (1) control group goal desire to the initial goal desire levels of participants in the two self-regulatory task conditions, and (2) post-manipulation goal desire level in each self-regulatory task condition to the initial goal desire level in that condition within subjects. Note that our hypotheses suggest that there should be no difference in (1) in any of the three groups (control, implementation planning, remembering past actions) for both volitionally selected and assigned goals. However, there should be a significant difference in (2) for assigned goals but not for volitionally selected goals.

\section{Results}

Initial levels of goal desire by goal type

Separate 3 self-regulatory strategy (plan, past actions, control) ANOVAs were conducted for volitionally selected and assigned goals with initial goal desire as the dependent variable. For volitionally selected goals, as expected, differences between groups were not significant $\left(M_{\text {plan }}=6.07, M_{\text {pastaction }}=6.08\right.$ vs. $\left.M_{\text {control }}=5.80, F(2,77)=0.89, p>0.41\right)$. A similar pattern of results was obtained for assigned goals as well $\left(M_{\text {plan }}=4.18, M_{\text {pastaction }}=4.53\right.$ vs. $\left.M_{\text {control }}=3.98, F(2,77)=0.91, p>0.40\right)$. These results provide evidence that initial levels of goal desire were similar for respondents across the three conditions in the case of volitionally selected as well as assigned goals.

Differences in pre- and post- manipulation levels of goal desire by goal type

Paired-sample $t$-tests were performed to compare whether the level of goal desire changed after the manipulation. Considering assigned goals, both self-regulatory strategies resulted in significant increases in participants' goal desire. Forming an implementation plan increased goal desire from 4.18 to 4.44 $(t(26)=2.27, p<0.05)$. Likewise, remembering past actions also led to a statistically significant increase in goal desire from 4.53 to $4.92(t(24)=2.05, p<0.05)$. These results support the motivating role of the two self-regulatory strategies for assigned goals, showing that goal desire increases significantly when decision makers either form an implementation plan or remember their past actions.

For volitionally selected goals, the results were different. Forming an implementation plan changed goal desire level from 6.07 to $5.81(t(26)=1.89, p>0.07)$, whereas remembering past actions changed goal desire from 6.08 to $6.16(t(26)=0.81, p>0.42)$. In neither case was the difference statistically significant at the 
$p=0.05$ level. These results indicate that goal desire is not increased by either strategy for participants who have volitionally selected their goals. Together, these findings support and strengthen the findings of the first two experiments.

In spite of these findings, one weakness that should be acknowledged regarding the present research is the use of single measures in all the studies. One point in our favor is that the measures are the same as those from the BDB (2003) study which demonstrated their psychometric adequacy.

\section{GENERAL DISCUSSION}

\section{Summary of results and their implications}

An important element of decision making, especially for effortful decisions, is their successful enactment once they have been reached (Hoffman \& Yates, 2005). Indeed, one important objective of this paper is to advocate broadening the scope of decision making research to study decision implementation and enactment issues explicitly. Through the present research, we identified two distinct self-regulatory strategies by which effortful decision enactment can be facilitated by decision makers after they have either chosen or been assigned goals to pursue. Drawing upon recent action psychology research (Armitage, 2004; Brandstätter et al., 2001), one strategy is to formulate a detailed implementation plan. A second distinct strategy, not considered by previous research, is to remember actions performed successfully in the past to accomplish a similar goal. Using the adapted BDB model, focusing on motivational variables, in our experiments we consistently found both these strategies to have a significant motivational impact on the processes by which decision makers pursue decision enactment.

Contributing to both the behavioral decision making and the action psychology literatures, we found the effects of these two strategies for volitionally chosen and assigned goals to be different. For goals that are volitionally chosen by the decision maker, the strategy of either formulating an implementation plan or remembering past actions influences only the proximal implementation-related variables -implementation intentions, plan completeness, and goal realization. Their significant positive impact on goal realization, the ultimate dependent variable in this analysis, is a key finding, suggesting two distinct means that decision makers can use to aid in the enactment of their effortful decisions. Interestingly, neither of these strategies influenced the distal goal-related variables-goal desire, goal intentions, perceived self-efficacy, and implementation desires - for goals that decision makers had selected themselves. These findings suggest that, reaching the decision regarding a goal that one wants to pursue voluntarily, offers a natural point of separation for decision makers (from a motivational standpoint), where they change their orientation from choosing the goal that is at a higher level of abstraction, to the different and more specific task, of choosing and enacting behaviors to attain it.

Furthermore, the effects of both self-regulatory strategies are more widespread for goals that have been assigned to the decision maker. For such goals, the impact of formulating an implementation plan or remembering past actions extends throughout the BDB model, to both implementation- and goal-related motivational variables. A practical implication is that individuals and organizations that assign goals to be carried out may benefit from having people form plans or remember past actions (or both), at the time of assignment. It is noteworthy that we found consistent results in three different experiments, the first where the goal of studying 2 hours continuously on an upcoming weekend was assigned to students, and goal realization was elicited through self-reports, a second where the goal given was to visit a web site made available during a limited time frame, and goal realization was observed by recording participants' actual behavior, and a third where goal desire was measured pre- and post-manipulation.

While formulating an implementation plan involves a future-orientation, that is, "when, where, how, and how long will I act to attain my goal' and may involve cognitive processes of information acquisition, comparison, and choice, remembering past actions involves cognitive processes of retrospective memory, 
that is, 'when, where, how, and how long did I act last time to attain my goal.' As such, these two strategies have distinctly different cognitive bases. Emerging research on memory for actions suggests that retrieving self-performed actions from the past is relatively less effortful than information processing involved in formulating an implementation plan (Gollwitzer, 1999). Remembering past actions is similar in process to recognition memory for retrospective tasks (Zimmer \& Cohen, 2001). As such, in cases where decision makers have successfully reached effortful goals before, remembering past actions may offer a more appealing strategy for facilitating their decision's enactment, in light of our findings which show that effects of both strategies to be strikingly similar.

\section{Future research opportunities}

In the present research, we considered cases where decision makers had little difficulty in remembering their past actions. For example, the student participants in our first experiment had studied for two hours continuously on a week-end several times during the previous academic year; and could recall their preparatory and executional actions on prior occasions. Our findings are therefore consistent with recent research in the debiasing literature which shows that when individuals are asked to generate alternatives by accessing information from long-term memory, a mental simulation mind-set is induced, reducing susceptibility to biased decision making (Hirt, Kardes, \& Markman, 2004). But it is noteworthy that such a debiasing effect only occurs when decision makers find it easy to generate alternatives. In cases where alternative generation from memory is experienced as difficult, evidence suggests that bias is amplified instead (Sanna, Schwarz, \& Stocker, 2002). This occurs because the experienced ease of retrieval from long-term memory can serve as an informational cue, guiding decision making subsequently (Schwarz et al., 1991).

This line of research has direct implications for the strategy of remembering past actions. In particular, it raises interesting questions regarding effortful decision making where instances of successful past acting are difficult to remember. In such cases, instead of facilitating decision enactment, the strategy of remembering past actions may backfire, reducing the likelihood of goal realization relative to a control group, who has not used such a strategy. Similarly, remembering instances of failure instead of success could also have a detrimental effect. Further research is needed to study these issues, and will help us better understand the limits of remembering past actions. More generally, research that seeks to understand the psychological processes that occur when decision makers remember past actions, and how they differ from the effects of plans, is needed.

Relatively little is known about conditions where the use of previously employed actions or self-chosen implementation plans lead to non-attainment of the goal on a particular occasion or their consequences. We note that this is a natural outcome in many cases for effortful decisions. It is important to study both the consequences of failure of these strategies on the decision maker's subsequent motivation, persistence, emotional reactions, and self-efficacy perceptions, as well as how these strategies are modified for use by the decision maker on subsequent occasions.

We have studied the role of remembering past actions on goals where past experience is compatible with, and supports, future goal-directed behavior. Another interesting extension to the present research would be to study goals and plans that conflict with entrenched habits of the decision maker, which have been referred to as 'counterintentional habits' (Verplanken \& Faes, 1999; Wood et al., 2005). Examples of such effortful decisions are when a heavy smoker decides to quit smoking, or when an office-goer accustomed to driving to work alone chooses to conserve fuel and car-pool with one's colleagues instead.

In such cases, the two strategies we studied, in the words of Verplanken and Faes (1999), 'may constitute opposing forces that are will-based and experience-based, respectively' (p. 595). To study which strategy dictates behavior is an important research topic, raising the question of what motivational intensity implies in the case of implementation plans and counterintentional habits, and how to compare one to the other (see 
Bagozzi \& Dholakia, 2005, for a detailed discussion of this issue). In sum, the self-regulatory strategies of forming implementation intentions and remembering past actions can be used, potentially, for creating or breaking habits, as well as inducing novel behaviors.

Finally, it would be interesting to study differences in decision making for volitionally chosen and assigned goals. One interesting preliminary finding that deserves further attention is the stronger relationship of goal desire with the implementation-related variables for assigned goals when compared to volitionally chosen goals. It could be that decision makers are not very good planners for their own goals (for instance, they don't consider issues such as plan completeness in depth) unless they are requested to do so. Likewise, the role played by the two self-regulatory strategies for different types of volitionally selected and assigned goals also deserves further research attention.

\section{ACKNOWLEDGEMENTS}

We wish to thank Sangwon Lee and Munira Sunelwala for their research assistance, and the reviewers and the associate editor for helpful comments on previous versions of this paper.

\section{REFERENCES}

Ajzen, I. (1991). The theory of planned behavior. Organizational Behavior and Human Decision Processes, 50, $179-211$. Ajzen, I. (2002). Residual effects of past on later behavior: Habituation and reasoned action perspectives. Personality \& Social Psychology Review, 6(2), 107-122.

Albarracín, D., \& Wyer, R. S., Jr. (2000). The cognitive impact of past behavior: Influences on beliefs, attitudes, and future behavioral decisions. Journal of Personality and Social Psychology, 79(1), 5-22.

Arkes, H. R., \& Ayton, P. (1999). The sunk cost and Concorde effects: Are humans less rational than lower animals? Psychological Bulletin, 125, 591-600.

Armitage, C. J. (2004). Evidence that implementation intentions reduce dietary fat intake: A randomized trial. Health Psychology, 23(3), 319-323.

Bagozzi, R. P., \& Dholakia, U. M. (1999). Goal setting and goal striving in consumer behavior. Journal of Marketing, 61, 19-32.

Bagozzi, R. P., \& Dholakia, U. M. (2005). The role of experience in goal setting and goal striving. In T. Betsch, \& S. Haberstroh (Eds.), The routines of decision making (pp. 21-38). Mahwah, NJ: LEA.

Bagozzi, R. P., Dholakia, U. M., \& Basuroy, S. (2003). How effortful decisions get enacted: The motivating role of decision processes, desires, and anticipated emotions. Journal of Behavioral Decision Making, 16(4), $273-295$.

Bandura, A. (1997). Self-efficacy: The exercise of control. San Francisco: Freeman.

Bandura, A., \& Locke, E. A. (2003). Negative self-efficacy and goal effects revisited. Journal of Applied Psychology, 88(1), 87-99.

Baron, R. M., \& Kenny, D. A. (1986). The moderator-mediator variable distinction in social psychological research: Conceptual, strategic and statistical considerations. Journal of Personality and Social Psychology, 51(12), 1173-1182.

Beach, L. R. (1990). Image theory: Decision making in personal and organizational contexts. Chichester: Wiley.

Beach, L. R., \& Mitchell, T. R. (1998). The basics of image theory. In L. R. Beach (Ed.), Image theory: Theoretical and empirical foundations (pp. 3-18). Mahwah, NJ: LEA.

Betsch, T., Haberstroh, S., Glöckner, A., Haar, T., \& Fiedler, K. (2001). The effects of routine strength on adaption and information search in recurrent decision making. Organizational Behavior and Human Decision Processes, 84, $23-53$.

Betsch, T., Haberstroh, S., Molter, B., \& Glöckner, A. (2004). Oops, I did it again-relapse errors in routinized decision making. Organizational Behavior and Human Decision Processes, 93, 62-74.

Brandstätter, V., \& Frank, E. (2002). Effects of deliberative and implemental mindsets on persistence in goal-directed behavior. Personality and Social Psychology Bulletin, 28(10), 1366-1378.

Brandstätter, V., Lengfelder, A., \& Gollwitzer, P. M. (2001). Implementation intentions and efficient action initiation. Journal of Personality and Social Psychology, 81(5), 946-960.

Carver, C. S., \& Scheier, M. F. (1998). On the self-regulation of behavior. Cambridge, UK: Cambridge University Press. 
Crockett, L. J. (2002). Agency in the life course: Concepts and Processes. In L. J. Crockett (Ed.), Agency, motivation, and the life course. Volume 48 of the Nebraska symposium on motivation (pp. 1-31). Lincoln Nebraska: University of Nebraska Press.

Deci, E. L., \& Ryan, R. M. (2000). The 'what' and 'why' of goal pursuits: Human needs and the self-determination of behavior. Psychological Inquiry, 11(4), 227-268.

Dholakia, U. M., \& Bagozzi, R. P. (2002). Mustering motivation to enact decisions: How decision process characteristics influence goal realization. Journal of Behavioral Decision Making, 15, 167-188.

Dholakia, U. M., \& Bagozzi, R. P. (2003). As time goes by: How goal and implementation intentions influence enactment of short-fuse behaviors. Journal of Applied Social Psychology, 33(5), 889-922.

DiClemente, C. C., Prochaska, J. O., \& Gilbertini, M. (1985). Self-efficacy and the stages of self-change in smoking. Cognitive Therapy and Research, 9, 181-200.

Erez, M., Gopher, D., \& Arzi, N. (1990). Effects of goal difficulty, self-set goals, and monetary rewards on dual task performance. Organizational Behavior and Human Decision Processes, 47(2), 247-269.

Gollwitzer, P. M. (1996). The volitional benefits of planning. In P. M. Gollwitzer, \& J. A. Bargh (Eds.), The psychology of action: Linking cognition and motivation to behavior (pp. 287-312). New York: Guilford Press.

Gollwitzer, P. M. (1999). Strong effects of simple plans. American Psychologist, 54(7), 493-503.

Gollwitzer, P. M., \& Brandstätter, V. (1997). Implementation intentions and effective goal pursuit. Journal of Personality and Social Psychology, 73(1), 186-199.

Gollwitzer, P. M., Heckhausen, H., \& Ratajczak, H. (1990). From weighing to willing: Approaching a change decision through pre- or post-decisional implementation. Organizational Behavior and Human Decision Processes, 45(1), 41-65.

Heckhausen, H., \& Kuhl, J. (1985). From wishes to action: The dead ends and short cuts on the long way to action. In M. Frese, \& J. Sabini (Eds.), Goal-directed behavior: Psychological theory and research on action (pp. 134-160). Hillsdale, NJ: Erlbaum.

Hirt, E. T., Kardes, F. R., \& Markman, K. D. (2004). Activating a mental simulation mind-set through generation of alternatives: Implications for debiasing in related and unrelated domains. Journal of Experimental Social Psychology, 40, 374-383.

Hoffman, R. R., \& Yates, J. F. (2005). Decision(?) making (?). IEEE Intelligent Systems, 20(4), 76-83.

Kahneman, D., Knetsch, J. L., \& Thaler, R. (1991). The endowment effect, loss aversion, and status quo bias. Journal of Economic Perspectives, 5(1), 193-206.

Kvavilashvili, L., \& Ellis, J. (1996). Varieties of intention: Some distinctions and classifications. In M. Brandimonte, G. O. Einstein, \& M. A. McDaniel (Eds.), Prospective memory: Theory and applications (pp. 23-51). Mahwah, NJ: LEA.

Latham, G. P., \& Saari, L. M. (1979). The effects of holding goal difficulty constant on assigned and participatively set goals. Academy of Management Journal, 22, 163-168.

Lepper, M., \& Gilovich, T. J. (1981). The psychological functions of reward: A social-developmental perspective. In S. S. Brehm, S. M. Kasin, \& F. X. Gibbons (Eds.), Developmental social psychology (pp. 5-31). New York: Oxford University Press.

Locke, E. A., Alavi, M., \& Wagner, J. (1997). Participation in decision making: An information exchange perspective. In G. Ferris (Ed.), Research in personnel and human resources management (Vol. 15, pp. 293-331). Greenwich, CT: JAI Press.

Locke, E. A., \& Latham, G. P. (2002). Building a practically useful theory of goal-setting and motivation. American Psychologist, 57, (September), 705-717.

Locke, E. A., Latham, G. P., \& Erez, M. (1988). The determinants of goal commitment. Academy of Management Review, 13(1), 23-29.

Manstead, A. S. R., \& van Eekelen, S. A. M. (1998). Distinguishing between perceived behavioral control and self-efficacy in the domain of academic intentions and behaviors. Journal of Applied Social Psychology, 28(15), $1375-1392$.

Meyer, J. S., \& Rebok, G. W. (1985). Planning-in-action across the life span. In T. M. Shlecter, \& M. P. Toglia (Eds.), New directions in cognitive sciences (pp. 47-68). Norwood, NJ: Ablex.

Miller, E. T., \& Marlatt, G. A. (1998). How to keep up with those New Year's resolutions, researchers find commitment is the secret of success. Available at http://www.washington.edu/newsroom/news/1997archive/1297archive/ k122397.html.

Ouellette, J. A., \& Wood, W. (1998). Habit and intention in everyday life: The multiple processes by which past behavior predicts future behavior. Psychological Bulletin, 124(1), 54-74.

Perugini, M., \& Conner, M. (2000). Predicting and understanding behavioral intentions: The interplay between goals and behaviors. European Journal of Social Psychology, 30, 705-731.

Sanna, L. J., Schwarz, N., \& Stocker, S. L. (2002). When debiasing backfires: Accessible content and accessibility experiences in debiasing hindsight. Journal of Experimental Psychology: Learning, Memory and Cognition, 28, 497-502. 
Schwarz, N., Bless, H., Strack, F., Klumpp, G., Rittenauer-Schatka, H., \& Simons, A. (1991). Ease of retrieval as information: Another look at the availability heuristic. Journal of Personality and Social Psychology, 61, $195-202$.

Sheeran, P., \& Orbell, S. (2000). Using implementation intentions to increase attendance for cervical cancer screening. Health Psychology, 18, 283-289.

Sheeran, P., Webb, T. L., \& Gollwitzer, P. M. (2005). The interplay between goal intentions and implementation intentions. Personality and Social Psychology Bulletin, 31(1), 87-98.

Sobel, M. E. (1982). Asymptotic confidence intervals for indirect effects in structural equation models. In S. Leinhardt (Ed.), Sociological methodology 1982 (pp. 290-312). Washington, DC: American Sociological Association.

Sue-Chan, C., \& Ong, M. (2002). Goal assignment and performance: Assessing the mediating roles of goal commitment and self-efficacy and the mediating role of power distance. Organizational Behavior and Human Decision Processes, 89, 1140-1161.

Svenson, O. (1997). Differentiation and consolidation theory. In R. Flin, E. Salas, M. Strub, \& L. Martin (Eds.), Decision making under stress: Emerging theories and applications (pp. 301-314). UK: Aldershot.

Terry, D. J., \& O'Leary, J. E. (1995). The theory of planned behavior: The effects of perceived behavioural control and self-efficacy. Journal of Social Psychology, 34(2), 199-220.

Triandis, H. C. (1980). Values, attitudes, and interpersonal behavior. In H. E. Howe, \& M. M. Page (Eds.), Nebraska symposium on motivation 1979. Lincoln Nebraska: University of Nebraska Press.

Verplanken, B., Aarts, H., \& Van Knippenberg, A. (1997). Habit, information acquisition, and the process of making travel mode choices. European Journal of Social Psychology, 27, 539-560.

Verplanken, B., \& Faes, S. (1999). Goal intentions, bad habits, and effects of forming implementation intentions for healthy eating. Journal of Social Psychology, 29, 591-604.

Wood, W., Quinn, J., \& Kashy, D. (2002). Habits in everyday life: Thought, emotion, and action. Journal of Personality and Social Psychology, 83, 1281-1297.

Wood, W., Tam, L., \& Guerrero Witt, M. (2005). Changing circumstances, disrupting habits. Journal of Personality and Social Psychology, 88, 918-933.

Yates, J. F. (1990). Judgment and decision making. Englewood Cliffs, NJ: Prentice Hall.

Zimmer, H. D., \& Cohen, R. L. (2001). Remembering actions: A specific type of memory? In H. D. Zimmer , R. L. Cohen, M. J. Guynn, J. Engelkamp, R. Kormi-Nouri, \& M. A. Foley (Eds.), Memory for action: A distinct form of episodic memory (pp. 3-24). Oxford, UK: Oxford University Press.

Authors' biographies:

Utpal M. Dholakia is an Associate Professor of management in the Jesse H. Jones Graduate School of Management, Rice University. His research interests lie in studying relational aspects of customer behavior, motivational psychology of consumers and online marketing issues such as virtual communities and online auctions. Among others, Dr Dholakia's research has been published in Marketing Science, the Journal of Marketing, the Journal of Consumer Research, and the Journal of Behavioral Decision Making.

Richard P. Bagozzi is a Professor of Marketing at the Ross School of Business, and Professor in the department of Social and Administrative Sciences at the University of Michigan. Professor Bagozzi does basic research into personal and social action, human emotions, goal setting and goal striving, the role of culture in decision making, and social identity. This work has been applied in the areas of salesforce behavior, body weight maintenance and loss, exercising and dieting, consumer behavior, organization behavior, virtual communities, and various health contexts.

Mahesh Gopinath is an Associate Professor of marketing at College of Business and Public Administration, Old Dominion University, Norfolk, VA. His primary area of research is in the area of consumption emotions. His other areas of research include topics related to consumer psychology.

Authors' addresses:

Utpal M. Dholakia, Rice University, 6100 Main Street, MS 531, Houston TX 77005, USA.

Richard P. Bagozzi, Stephen M. Ross School of Business, University of Michigan, 701 Tappan St., Ann Arbor, MI 48109-1234, USA.

Mahesh Gopinath, College of Business and Public Administration, Old Dominion University, Norfolk, VA 23529, USA. 